\title{
Thyroid screening in prediabetes: Does it have any role?
}

\author{
Thapa $\mathrm{S}^{1 *}$, Gyawali $\mathrm{P}^{1}$, Tamrakar $\mathrm{R}^{2}$, Risal $\mathrm{P}^{1}$ \\ ${ }^{1}$ Department of Clinical Biochemistry, Kathmandu University School of Medical Sciences, Dhulikhel, Nepal \\ ${ }^{2}$ Department of Internal Medicine, Kathmandu University School of Medical Sciences, Dhulikhel, Nepal
}

\begin{abstract}
Background: Thyroid dysfunction and hyperglycemia are common metabolic problem. Unrecognized thyroid dysfunction may amplify existing cardiovascular disease risk in hyperglycemic subjects. Early recognition and management of thyroid dysfunction helps to control blood glucose and prevent associated morbidity. The aim of this study was to assess thyroid function among prediabetics and compare it with healthy controls. Methods: This study conducted in Kathmandu University hospital was reviewed and approved by Institutional review committee. The total of 200 participants were recruited for the study among which 106 were prediabetics (HbA1c 5.7-6.4\%) and 94 apparently healthy controls $(\mathrm{HbA} 1 \mathrm{c}<5.7 \%)$. We excluded known cases of diabetes mellitus, thyroid disorder, pregnant and those on medications that interfere with thyroid function and/or glucose metabolism. Results: Among the total participants 57.5\% (115) were female and $42.5 \%$ (85) were male. Prediabetics had significantly higher TSH $3.0(2.0,4.9)$ in comparison to the control $2.61(2.0,3.9)$ population $(\mathrm{p}=0.004)$. Serum TSH was raised in $42(21 \%)$ participants while $158(79 \%)$ had normal thyroid function. The association between prediabetes and thyroid dysfunction was significant $(\mathrm{p}=0.04$ ) with $26.4 \%$ of prediabetics having thyroid dysfunction compared to $14.9 \%$ in normal group. Thyroid dysfunction was independently associated with prediabetes $(\mathrm{OR}=2.38 ; 95 \% \mathrm{CI}: 1.17-4.17)$. Conclusions: Thyroid dysfunction is common finding among those with prediabetes. The cause of thyroid abnormality should be ascertained and treated appropriately to reduce the progression to diabetes mellitus and related complications. Though not routinely practiced, screening of thyroid disorder in patients with hyperglycemia could be beneficial.
\end{abstract}

Key Words: Hyperglycemia, Prediabetes, Thyroid dysfunction, Screening

\section{Introduction}

Thyroid dysfunction and diabetes mellitus (DM) are the two most common endocrine disorders. ${ }^{1}$ The prevalence of DM is increasing and is projected to rise up to 366 million worldwide in $2030 .^{2}$ In a study done in urban populations of Nepal the prevalence of diabetes, impaired glucose tolerance (IGT) and impaired fasting glycaemia (IFG) were $19.0 \%, 10.6 \%$ and $9.9 \%$ respectively. ${ }^{3}$ Similarly, the prevalence of thyroid dysfunction is also increasing. In a hospital based retrospective chart study, the prevalence of thyroid dysfunction was $29.0 \%$ in

\section{Correspondence Author}

Dr. Saroj Thapa, MBBS, MD, Lecturer,

Department of Clinical Biochemistry,

Kathmandu University School of Medical Sciences,

Dhulikhel, Nepal, Mobile No.: +977-9841276674,

Email: drsarojthapa@gmail.com
Tribhuwan University Teaching Hospital, ${ }^{4}$ and 25\% in Kathmandu University Teaching hospital. ${ }^{5}$

Hyperglycemia and thyroid disease are linked closely. Both of these conditions frequently coexist and the prevalence of thyroid dysfunction in diabetes patients is higher. ${ }^{6}$ Unrecognized thyroid dysfunction may amplify existing cardiovascular disease risk in hyperglycemic subjects. Early recognition and management of thyroid dysfunction helps to control blood glucose and prevent associated morbidity. Most of the studies have focused thyroid dysfunction among diabetic population. Very few studies till date have explored the status of thyroid among prediabetic population. Similarly the screening strategy for thyroid dysfunction in relation with blood sugar is not known. The aim 
of this study was to assess thyroid function among prediabetics and compare it with healthy controls.

\section{Methods}

This hospital based comparative cross sectional study was conducted at Dhulikhel hospital Kathmandu University hospital, Dhulikhel, Nepal from January 2018 to December 2018. The total of 200 participants was recruited for the study among which 106 were prediabetics and 94 apparently healthy controls. The prediabetics cases were defined according to American Diabetes Association (ADA) based on elevated Glycated haemoglobin (HbA1c) level (5.7-6.4\%) and control were those with normal HbA1c level $(<5.7 \%) .7 \mathrm{We}$ excluded those with known diabetes mellitus or on oral hypoglycemic drug/insulin therapy, pregnancy, those on medications that interfere with thyroid function and those who had known thyroid disease or history of thyroid surgery or radioiodine uptake. Informed written consent was obtained from all the participants before the commencement of the study. The ethical clearance for this study was provided by the institutional research committee, Dhulikhel Hospital.

Free thyroxine (fT4) and thyroid stimulating hormone (TSH) were determined from fasting morning sample by chemiluminescence assay (CLIA) using LIASION TSH assay (Diasorin). Fasting blood glucose was measured by glucose oxidase-peroxidase method using Biosystem analyzer (Bio system Spain, BA-400). Glycated hemoglobin (HbAlc) concentration was measured byhigh performance liquid chromatography(HPLC) method in ERBA Mannheim's Hb-Vario. Thyroid dysfunction was defined as clinical hypothyroidism with $\mathrm{fT} 4<0.8 \mathrm{ng} / \mathrm{dl}$ and $\mathrm{TSH}>3.6 \mathrm{mIU} / \mathrm{ml}$; clinical hyperthyroidism with $\mathrm{fT} 4>1.7 \mathrm{ng} / \mathrm{dl}$ and $\mathrm{TSH}<0.3$ $\mathrm{mIU} / \mathrm{ml}$; subclinical hypothyroidism with $\mathrm{fT} 4: 0.8$ $1.7 \mathrm{ng} / \mathrm{dl}$ and $\mathrm{TSH}>3.6 \mathrm{mIU} / \mathrm{ml}$; Subclinical hyperthyroidism with fT4: $0.8-1.7 \mathrm{ng} / \mathrm{dl}$ and $\mathrm{TSH}<0.3 \mathrm{mIU} / \mathrm{ml}$.
Data was collected and entered using Microsoft Excel $^{\text {TM }} 2010$ and analyzed using IBM SPSS version 11.5 (SPSS inc. Chicago, Illinois, USA). Data was expressed in terms of percentage, mean \pm standard deviation and median (Inter Quartile Range).

All data sets were tested for normal distribution using the Kolmogorov-Smirnov-test. Significant differences between groups were calculated using chi-square tests for the percentages and independent sample t-test or the Wilcoxon signed rank test for the mean/median values. Spearman correlation analysis was conducted to assess the correlation between quantitative variables. The odds ratios (OR) and 95\% confidence intervals (CI) were calculated. A two-tailed alpha with $\mathrm{P}<0.05$ was considered statistically significant for all analyses

\section{Results}

The study population comprised of $106(53 \%)$ participants with prediabetes and 94 (47\%) apparently healthy controls. Among the total participants, $115(57.5 \%)$ were female and 85 $(42.5 \%)$ were male. The mean age of the participants was $32.9 \pm 6.4$ years with the range of 20 through 53 years. The mean concentration of fasting blood glucose (FBS) was $90 \pm 13.6 \mathrm{mg} / \mathrm{dl}$; HbAlc was $5.6 \pm 0.4 \%$, while that of fT4 was $1.0 \pm 0.1 \mathrm{ng} / \mathrm{dl}$. The median TSH concentration among the participants was $3.0(2.0,4.03) \mathrm{mIU} / \mathrm{ml}$. The baseline characteristic of the participants is shown in table 1. Prediabetics had significantly higher body mass index (BMI), systolic and diastolic blood pressure compared with the apparently healthy controls as shown in table 1. 
Table 1: Baseline characteristics of the study population

$\left.\begin{array}{|c|c|c|c|}\hline \text { Characteristics } & \text { Prediabetic }(\mathrm{n}=106) & \text { Control }(\mathrm{n}=94) & \text { P value } \\ \hline \text { Age (years) } & 34.6 \pm 6.4 & 30.9 \pm 5.8 & <0.01 \\ \hline \mathrm{BMI}\left(\mathrm{kg} / \mathrm{m}^{2}\right) & 26.1 \pm 2 & 23.4 \pm 2.2 & <0.01 \\ \hline \text { Systolic blood } \\ \text { pressure }(\mathrm{mmHg})\end{array}\right)$

\section{Data expressed as mean \pm SD}

The comparison of biochemical parameters between the two groups is shown in table 2. Thyroid stimulating hormone was significantly higher in prediabetic group compared with the controls. Serum fT4 was lower in the prediabetic group as shown in table 2 .

Table 2: Comparison of biochemical parameters in study population

\begin{tabular}{|c|c|c|c|}
\hline $\begin{array}{c}\text { Biochemical } \\
\text { Parameters }\end{array}$ & Prediabetic $(\mathrm{n}=106)$ & Control $(\mathrm{n}=94)$ & P value \\
\hline $\begin{array}{c}\text { Fasting blood } \\
\text { sugar (FBS) }\end{array}$ & $96.5 \pm 13.3$ & $82.8 \pm 9.9$ & $<0.01$ \\
\hline $\mathrm{HbA} 1 \mathrm{c}(\%)$ & $5.9 \pm 0.09$ & $5.2 \pm 0.3$ & $<0.01$ \\
\hline $\mathrm{TSH}(\mathrm{mlU} / \mathrm{ml})$ & $3.0(2.0,4.9)$ & $2.61(2.0,3.9)$ & 0.004 \\
\hline $\mathrm{fT}_{4}(\mathrm{ng} / \mathrm{dl})$ & $0.9 \pm 0.1$ & $1.01 \pm 0.13$ & 0.22 \\
\hline
\end{tabular}

Data expressed as mean $\pm \mathrm{SD}$, Median (25th percentile, 75th percentile)

$$
\text { - } 5 \text { - }
$$


Serum TSH was raised in 42 (21\%) participants while 158 (79\%) had normal thyroid function. Among those with thyroid dysfunction, 41 had subclinical hypothyroidism and one participant had clinical hypothyroidism. The association between prediabetes and thyroid dysfunction was significant $(\mathrm{p}=0.04)$ with $26.4 \%$ of prediabetics having thyroid dysfunction compared to $14.9 \%$ in normal group as shown in table 3. In our study population, thyroid dysfunction was independently associated with prediabetes $(\mathrm{OR}=2.38 ; 95 \% \mathrm{CI}: 1.17-4.17)$. Subclinical hypothyroidism was the most common thyroid dysfunction in both groups of participants.

Table 3: Association of Thyroid dysfunction among the participants.

\begin{tabular}{|c|c|c|c|}
\hline & Euthyroid $(\mathrm{n}=158)$ & $\begin{array}{c}\text { Thyroid dysfunction } \\
(\mathrm{n}=42)\end{array}$ & P value \\
\hline $\begin{array}{c}\text { Healthy Control }(\mathrm{n}= \\
94)\end{array}$ & $80(85.1 \%)$ & $14(14.9 \%)$ & \multirow{2}{*}{0.04} \\
\hline Prediabetic $(\mathrm{n}=106)$ & $78(73.6 \%)$ & $28(26.4 \%)$ & \\
\hline
\end{tabular}

The scatter plot showing the distribution of TSH and Glycated hemoglobin (HbA1c) concentration among the participants is shown in figure 1. Similarly, the correlation between fasting blood sugar (FBS) and TSH is also shown in figure 1. The correlation between the TSH and HbAlc as well as with RBS was weak.
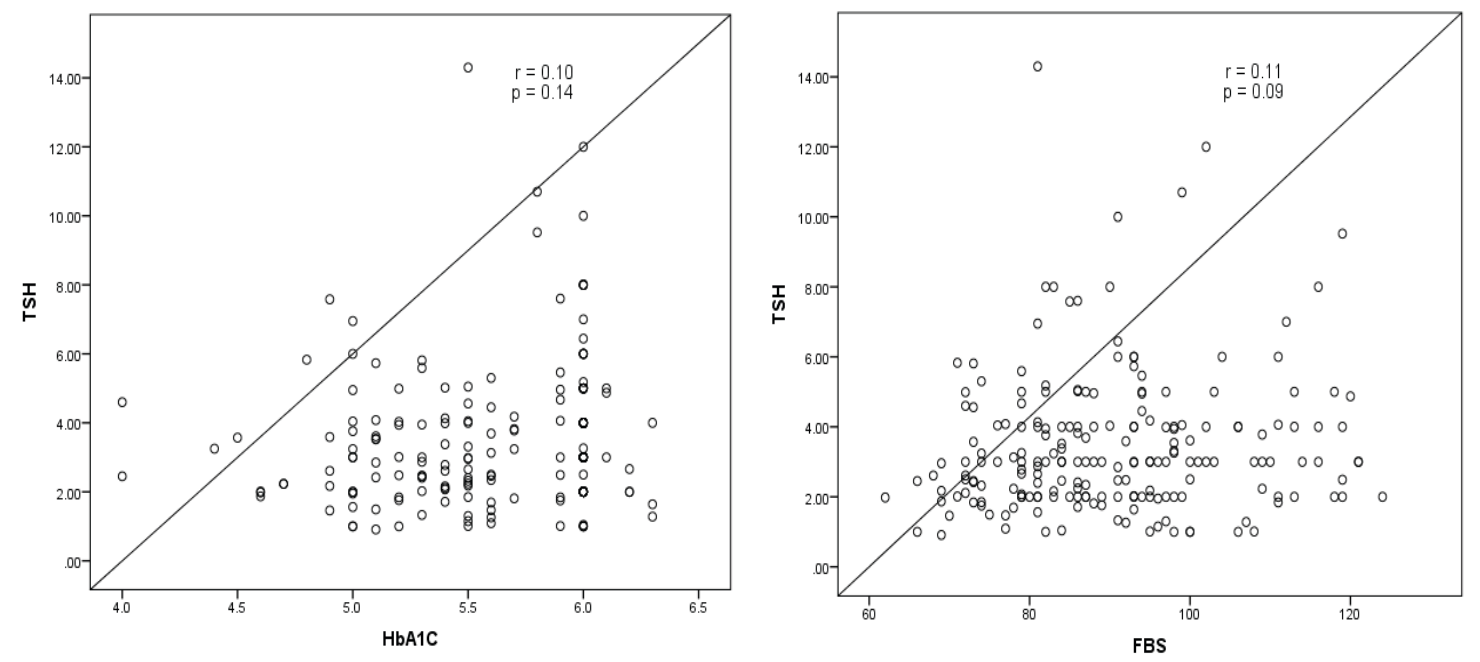

Figure 1: Scatter plot showing the distribution and relation of TSH with HbA1c $(r=0.010, p=0.14)$ and Fasting blood sugar $(r=0.11, p=0.09)$. 


\section{Discussion:}

Hyperglycemia and thyroid disease are linked closely and the prevalence of thyroid dysfunction was reported to be higher in diabetes patients compared to general population.6 In the present study the prevalence of thyroid dysfunction was $26.4 \%$ among the prediabetics which was higher than the normal population (14.9\%). Similar to our study, the prevalence of thyroid dysfunction was $19.3 \%$ and $13.5 \%$ among prediabetics and healthy controls in a follow up study conducted in Tehran. The odds ratio of developing thyroid dysfunction among prediabetics in that study was 1.03 with $95 \%$ CI: $0.77-1.38 .8$ The odds ratio and $95 \% \mathrm{CI}$ was lower compared to our study. The prevalence rate of thyroid dysfunction among diabetes patients is found in between $10.8 \%$ to $45 \%$ in different studies. ${ }^{6,}$ 9-12 Significantly higher prevalence of thyroid dysfunction among diabetics was found in a study conducted in Jordan. ${ }^{12}$ Similarly, the prevalence of $12.3 \%$ in Greece and 16\% in Saudi Arabia was reported by Akbar et in patients with diabetes mellitus. ${ }^{13}$ The most common thyroid disorder in the present study was subclinical hypothyroidism. Almost all cases of thyroid dysfunction among healthy controls and prediabetics were subclinical hypothyroidism. Subclinical hypothyroidism was the most common thyroid dysfunction in other studies as well. ${ }^{8}$

Subclinical hypothyroidism is a frequent finding in patients with diabetes mellitus. The level of TSH may predict the development to clinical hypothyroidism in patients with diabetes. Those with high concentration of TSH at diagnosis of diabetes are more likely to develop clinical hypothyroidism. In a retrospective study investigating 1100 diabetes patients, the baseline TSH concentrations of $>2.2 \mathrm{mIU} / \mathrm{L}$ was predictive for development of hypothyroidism. ${ }^{14}$ Insulin resistance is frequent finding in those with subclinical hypothyroidism. This may be due to ineffective insulin stimulated glucose transport caused by decreased expression of glucose transporters. Treatment of hypothyroidism has shown to restore insulin sensitivity and the secretion of glucose regulatory hormones. ${ }^{15}$ Furthermore, hypothyroidism is associated with several components of the metabolic syndrome and could therefore indirectly relate to the increased risk of diabetes. ${ }^{16}$

We did not find any significant correlation between thyroid hormones and $\mathrm{HbAlc}$ in the present study. In a study done to detect pre diabetes in hypothyroid patients in Iran, significant positive correlation was found between TSH and HbAlc $(\mathrm{p}=0.007$, $\mathrm{r}=0.469) .{ }^{17}$ Though not significantly correlated, concentration of TSH was significantly higher in the prediabetic group compared to healthy controls in our study. In a population based cohort study, Chakeret. al. reported risk of progression from prediabetes to diabetes was higher with low-normal thyroid function. ${ }^{18}$ The study concluded that low and low-normal thyroid function is risk factors for incident diabetes, especially in individuals with prediabetes. According to that study, the risk of developing diabetes was 1.13 times higher for every doubling of TSH levels among prediabetics.18 In contrast to our study and most other studies, Danish nationwide registry study have reported an increased association between diabetes and hyperthyroidism. ${ }^{19}$

The difference in the prevalence of thyroid dysfunction in patients with hyperglycemia may be due to the diversity of assay used to measure thyroid function tests. Apart from this the upper and lower reference range of thyroid 
stimulating hormone is also variable. In our study we have revised the manufacturer's upper reference range of TSH from $3.5 \mathrm{mIU} /$ $\mathrm{ml}$ to $4.5 \mathrm{mIU} / \mathrm{ml}$. The variation may be due to the definition of the conditions, particularly of thyroid dysfunction. It may be also due to the difference in the design of the studies and selection of the participants from a cohort. Possible iodine status of the studied population was not in account in most of the studies which could be the cause of variability.

Currently, there are not any guidelines that recommend thyroid screening in prediabetics and patients at risk of diabetes. But, different associations around the world have recommended guidelines for thyroid screening in patients with diabetes. ${ }^{20-22}$ Perros et. al. also have suggested that testing for thyroid dysfunction in patients with diabetes mellitus is necessary and should be carried out annually. ${ }^{6}$ There are wide variations in the different guidelines in thyroid screening in diabetes patients. ${ }^{23}$ It is generally recommended for thyroid screening in diabetes if autoimmune disease is suspected. ${ }^{23}$ In individuals with risk of diabetes and hypothyroidism, lifestyle modification and initialization of hypothyroid treatment could be started earlier which may prevent from developing overt diabetes. Thus thyroid screening using high sensitive assay for TSH should be used in all individuals with increased risk of diabetes. There is still much more to be explored to find out the relation between thyroid dysfunction and hyperglycemia. Future studies should focus on screening strategies as well as effectiveness of early treatment of hypothyroidism in individuals with prediabetes.

There are several limitations of our study. It was a cross-sectional study which lacked assessment of temporality. Other cause of thyroid dysfunction including iodine status of the participants was not ascertained in our study. Similarly, we could not test the antibodies related to thyroid dysfunction. We also did not carry out the standard oral glucose tolerance test to diagnose prediabetes participants that have been included in this study.

Increased serum TSH is common finding among those with prediabetes. The cause of thyroid abnormality should be ascertained and treated appropriately to reduce the progression to diabetes mellitus and related complications. Though not routinely practiced, screening of thyroid disorder in patients with hyperglycemia could be beneficial.

\section{Conclusion}

Increased serum TSH is common finding among those with prediabetes. The cause of thyroid abnormality should be ascertained and treated appropriately to reduce the progression to diabetes mellitus and related complications. Though not routinely practiced, screening of thyroid disorder in patients with hyperglycemia could be beneficial.

\section{Acknowledgement}

Our sincere thanks to all the technical staffs of the department of clinical biochemistry, Dhulikhel Hospital Kathmandu University Hospital.

\section{References}

1. Duntas LH, Orgiazzi J, Brabant G. The interface between thyroid and diabetes mellitus. Clinical endocrinology. 2011;75(1):1-9.

2. Rathmann W, Giani G. Global prevalence of diabetes: estimates for the year 2000 and projections for 2030 . Diabetes care. 2004;27(10):2568-9.

3. Shrestha U, Singh D, Bhattarai M. The prevalence of hypertension and diabetes defined by fasting and 2-h plasma glucose criteria in urban Nepal. Diabetic medicine. 2006;23(10):1130-5. 
4. Mahato R, Jha B, Singh K, Yadav B, Shah S, Lamsal M. Status of Thyroid disorders in Central Nepal: A Tertiary care Hospital based study. International Journal of Applied Sciences and Biotechnology. 2015;3(1):119-22.

5. Aryal M, Gyawali P, Rajbh N, Aryal P, Raj D. A prevalence of thyroid dysfunction in Kathmandu University Hospital, Nepal. Biomedical Research. 2010;21(4).

6. Perros P, McCrimmon R, Shaw G, Frier B. Frequency of thyroid dysfunction in diabetic patients: value of annual screening. Diabetic medicine. 1995;12(7):6227.

7. American Diabetes Association. 2. Classification and diagnosis of diabetes: standards of medical care in diabetes-2018. Diabetes care. 2018;41(Supplement 1):S13-S27.

8. Dehaki MG, Amouzegar A, Delshad H, Mehrabi Y, Tohidi M, Azizi F. Thyroid dysfunction in patients with impaired glucose metabolism: 11 year follow up from the Tehran Thyroid Study. PloS one. 2017;12(10):e0184808.

9. Diez J, Sánchez P, Iglesias P. Prevalence of thyroid dysfunction in patients with type 2 diabetes. Experimental and Clinical Endocrinology \& Diabetes. 2011;119(04):201-7.

10. Smithson M. Screening for thyroid dysfunction in a community population of diabetic patients. Diabetic medicine. 1998;15(2):148-50.

11. Al-Geffari M, Ahmad NA, Al-Sharqawi AH, Youssef AM, AlNaqeb D, Al-Rubeaan K. Risk factors for thyroid dysfunction among type 2 diabetic patients in a highly diabetes mellitus prevalent society. International journal of endocrinology. 2013;2013.

12. Radaideh A-RM, Mo MKN, Amari FL, Bateiha AE, El-Khateeb MPMS, Naser PAS, et al. diabetes mellitus in Jordan. Saudi Med J. 2004;25(8):1046-50.

13. Akbar D, Ahmed M, Al-Mughales J. Thyroid dysfunction and thyroid autoimmunity in Saudi type 2 diabetics. Acta Diabetologica. 2006;43(1):14-8.

14. Ramasamy V, Kadiyala R, Fayyaz F, Mallipedhi A, Baglioni P, Okosieme O. Value of baseline serum thyrotropin as a predictor of hypothyroidism in patients with diabetes mellitus. Endocrine Practice. 2010;17(1):26-32.

15. Stanická S, Vondra K, Pelikánová T, Vlček P, Hill M, Zamrazil V. Insulin sensitivity and counter-regulatory hormones in hypothyroidism and during thyroid hormone replacement therapy. Clinical Chemistry and Laboratory Medicine (CCLM). 2005;43(7):71520.

16. Iwen KA, Schröder E, Brabant G. Thyroid hormones and the metabolic syndrome. European thyroid journal. 2013;2(2):83-92.

17. Raghad A. Mohsin SNa, Khalid I.Al-Lehibi. Detection for Pre- diabetes in Hypothyroid Patients. International Journal of Advanced Research 2013;1(8):423-30.

18. Chaker L, Ligthart S, Korevaar TI, Hofman A, Franco $\mathrm{OH}$, Peeters RP, et al. Thyroid function and risk of type 2 diabetes: a population-based prospective cohort study. BMC medicine. 2016;14(1):150.

19. Brandt F, Thvilum M, Almind D, Christensen K, Green A, Hegedüs L, et al. Morbidity before and after the diagnosis of hyperthyroidism: a nationwide register-based study. PloS one. 2013;8(6):e66711.

20. Ladenson PW, Singer PA, Ain KB, Bagchi N, Bigos ST, Levy EG, et al. American Thyroid Association guidelines for detection of thyroid dysfunction. Archives of internal medicine. 2000;160(11):1573-5.

21. Baskin HJ, Cobin RH, Duick DS, Gharib H, Guttler RB, Kaplan MM, et al. American association of clinical endocrinologists medical Guidelines for clinical practice for the evaluation and treatment of hyperthyroidism and hypothyroidism: AACE Thyroid Task Force. Endocrine practice. 2002;8(6):457-69.

22. Beastall G, Beckett G, Franklyn J, Fraser W, Hickey J, John R, et al. UK Guidelines for the use of thyroid function tests. The association for Clinical Biochemistry. 2006.

23. Kadiyala R, Peter R, Okosieme O. Thyroid dysfunction in patients with diabetes: clinical implications and screening strategies. International journal of clinical practice. $2010 ; 64(8): 1130-9$. 